\title{
Aromas como fuente de investigación en el paisaje urbano
}

Mónica Susana de La Barrera Medina, Tonahtiuc Moreno Codina y Netzahualcóyotl López Flores

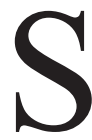

in duda, las ciudades nos impactan en diversos aspectos; el ámbito visual, por una parte, nos permite identificar por medio de fotografías por ejemplo el espacio conocido o asociarlo con lugares en los que ya hemos estado. Por otra parte, los sonidos juegan un papel importante debido a que los reconocemos, aun sin observar, de ahí que el tránsito vehicular, o el audio de determinado producto o servicio, nos pueda evocar recuerdos; sin embargo, otro de los sentidos, como el olfato, es protagonista de una reciente investigación por planificadores urbanos, en la cual se afirma que lo que olemos puede afectar incluso nuestro comportamiento y percepción de la ciudad.

Smelly Maps: The Digital Life of Urban Smellscapes, realizada por Daniele Quercia, Rossano Schifanella, Luca Maria Aiello y Kate McLean (2015), muestra el estudio realizado en siete ciudades, ${ }^{1}$ en las que se analizaron los aromas a través de smellwalks o "paseos de olor", clasificación que consistió en pedir a los lugareños caminar alrededor de su ciudad, identificar olores distintos y tomar notas ante una variedad de diferentes smellscapes ("paisajes de olor"), para registrar sus experiencias y dar cuenta de lo que en determinados lugares acontece. Finalmente, se registraron y clasificaron los aromas, dando como resultado el primer diccionario de olores.

Con este registro, se encontró que las palabras relacionadas con el olfato están mejor clasificadas en categorías propuestas en una "taxonomía del olor urbano": las emisiones del tráfico, los olores industriales, alimentos y bebidas, humo de tabacos, materiales de limpieza, olores sintéticos, los residuos, las personas y los animales, los olores de la naturaleza y materiales de construcción.

Ámsterdam, Pamplona, Glasgow, Edimburgo, Newport París y Nueva York (Brooklyn y Greenwich Village).
La imagen colectiva de la ciudad, como sabemos, puede construirse y mantenerse por las imágenes que formamos, pues los mapas mentales son claros en términos del esfuerzo mental (Lynch, 1960). Estudios urbanos han explorado cómo la imaginabilidad se ve afectada por la facilidad con que la gente aprende de memoria las imágenes visuales de ella, pero la memoria se ve influida no sólo por lo que vemos, sino también por lo que olemos. A largo plazo, la memoria y el olfato están estrechamente relacionados, incluso se retienen los recuerdos y el aroma, por periodos de tiempo mucho más largos que las imágenes (Engen, 1991). Es por ello que los olores nos pueden proporcionar una visión de la vida social de las ciudades, incluso se pueden utilizar como un marcador invisible para reforzar áreas socioeconómicas. Probablemente si sabemos a qué huele, estemos delimitando lugares sin siquiera saberlo.

Algunos factores contextuales de esta investigación describen que las ciudades tienen un impacto significativo en la detección de olores. Detallan el ejemplo del diseño cuadricular en Nueva York, que fomenta experiencias de olores co- 
lectivos a gran escala, ${ }^{2}$ ya que fue diseñada para facilitar el flujo de aire utilizando los vientos predominantes del oeste con el objetivo de disipar las mismas, portadoras de enfermedades de finales del siglo XVIII. Es evidente distinguir que en las ciudades, los horarios pueden ayudar a detectar ciertos aromas, por ejemplo, el café y la cultura durante el día, que pueden ser muy distintos de los que acontecen en el mismo espacio durante la noche.

Quizá el registro de aromas, independientemente de las técnicas usadas, es difícil de clasificar; sin embargo, esta propuesta de los investigadores es una interesante alternativa para comprender lo que acontece en espacios urbanos, por ende sociales, en los que se pueden realizar estudios sobre el impacto y el comportamiento de sus habitantes. Vale la pena revisar la publicación citada y plantear una propuesta con la metodología usada en estas siete ciudades, a fin de aplicarla en el territorio nacional, seguramente encontraremos que el aroma en las ciudades de Mé-

2 En octubre de 2005, un olor dulce de jarabe se detectó en toda la ciudad, y aunque era un olor agradable, se recibieron cientos de llamadas a los servicios de emergencia de la ciudad, ya que el aroma "revivió recuerdos de la infancia", pero en una ciudad asustada por el terrorismo, se elevaron las preocupaciones sobre algún ataque que pudiera estar sinuosamente envuelto "en el olor de la cocina de la abuela" (DePalma, 2005). xico puede tener su propia clasificación, y que, sin duda, impacta en las emociones de sus habitantes.

Ver la ciudad, escucharla y finalmente olerla es una tarea potencial para diseñadores, planificadores, y todo aquel involucrado con el trabajo de proyectar la organización, comunicación e identidad de un lugar que puede generar importantes contribuciones, por ello es recomendable leer este estudio en el que los autores se aventuraron a registrar estas experiencias.

\section{Fuentes de consulta}

DePalma, A. (2005). Good Smell Vanishes, But It Leaves Air of Mystery. The New York Times. October 29.

Engen, Trygg (1991). Odor Sensation and Memory. Raeger Publishers.

Quercia, D., Aiello, L., Schifanella, R.; and Mc Lean, K. (2015). Smelly Maps: The Digital Life of Urban Smellscapes. Recuperado el 13 de julio de 2015, en http://bit.ly/1 JHcqQm

Lynch, K. (1960). The Image of the City. Publication of the Joint Center for Urban Studies. EUA:The Mit Press. 